Titulo do Trabalho

\title{
A PRAÇA COMO PRÁTICA DE AÇÕES AMBIENTAIS: A EXPERIÊNCIA DO JARDIM DAS ROSAS - PRESIDENTE PRUDENTE/SP
}

Nome do Autor (a) Principal

Eliana Maria Alves Guimarães

Nome (s) do Coautor (a) (s)

José Antonio Moreno Lopes; Leonice Seolin Dias

Instituição ou Empresa

Faculdade de Ciências e Tecnologia/UNESP- Presidente Prudente/PP

E-mail de contato

lia.guima@gmail.com; morenoja@uol.com.br; nseolin@gmail.com.

Resumo: A praça como lugar para a realização de ações de Educação Ambiental se efetiva a cada encontro no projeto "Um bairro melhor" desenvolvido por um grupo de crianças e moradores do jardim das Rosas em Presidente Pudente/SP. O objetivo principal do grupo é sensibilizar e conscientizar os moradores para a conservação da limpeza da praça e do bairro e a importância da arborização para a cidade. Para alcançar os objetivos propostos são desenvolvidas inúmeras atividades - mutirão de limpeza da praça, teatro infantil, brincadeiras ambientais, reuniões de trabalho, plantio de árvores. Os resultados dessas ações são, além de aquisição de equipamentos urbanos para a praça, contribuir para construção de novos conhecimentos e práticas sustentáveis para a melhoria da qualidade de vida do bairro.

Palavras - chave: Educação ambiental; praça; práticas sustentáveis. 


\section{INTRODUÇÃO}

Neste trabalho apresenta-se um relato da experiência do grupo de Educação Ambiental do Jardim das Rosas de Presidente Prudente/SP. Esse grupo, chamado de Amigas da Natureza, tem como componentes seis crianças, entre nove e onze anos e mais três adultos, que além de fazerem parte do grupo, sistematizam e viabilizam as ações ambientais planejadas pela a equipe.

A proposta da Educação Ambiental difundida por esse grupo é a de promover a reflexão a respeito dos padrões insustentáveis no modo de agir com a natureza, como por exemplo, o não cultivo de plantas nos quintais e nas calçadas, o consumismo, especialmente, no que diz respeito à geração de lixo e sua disposição final; o desperdício de água etc.

O estilo de vida que a sociedade moderna pratica se tem caracterizado pelo uso intensivo dos recursos naturais (água, minérios, ar, solo, matas etc.), e, muitas vezes, não tem a devida reflexão de todos os processos envolvidos nessa dinâmica. Dessa maneira, as consequências desse processo mostram-se na poluição do ar, dos solos e das águas, comprometendo a qualidade ambiental e a qualidade de vida de toda a população.

É com base neste cenário de crise ambiental que se faz fundamental promover a Educação Ambiental. Segundo Sato (1995) os projetos de Educação Ambiental precisam ter os seguintes objetivos:

- Sensibilização Ambiental: processo de alerta, considerado como primeiro objetivo para alcançar o pensamento sistêmico da Educação Ambiental;

- Compreensão Ambiental: conhecimento dos componentes e dos mecanismos que regem o sistema natural.

- Responsabilidade Ambiental: reconhecimento do ser humano como principal protagonista para determinar e garantir a manutenção do planeta.

- Competência Ambiental: capacidade de avaliar e agir efetivamente no sistema.

- Cidadania Ambiental: capacidade de participar ativamente, resgatando os direitos e promovendo uma nova ética capaz de conciliar a natureza e a sociedade (1995, p.3).

O grupo de Educação Ambiental do Jardim das Rosas tem buscado a realização desses objetivos propostos pela autora. As ações são realizadas com o intuito de, no primeiro momento, sensibilizar os moradores, e, por isso, acontece o mutirão de limpeza, com varreção e catação do lixo da praça. Num segundo momento, são 


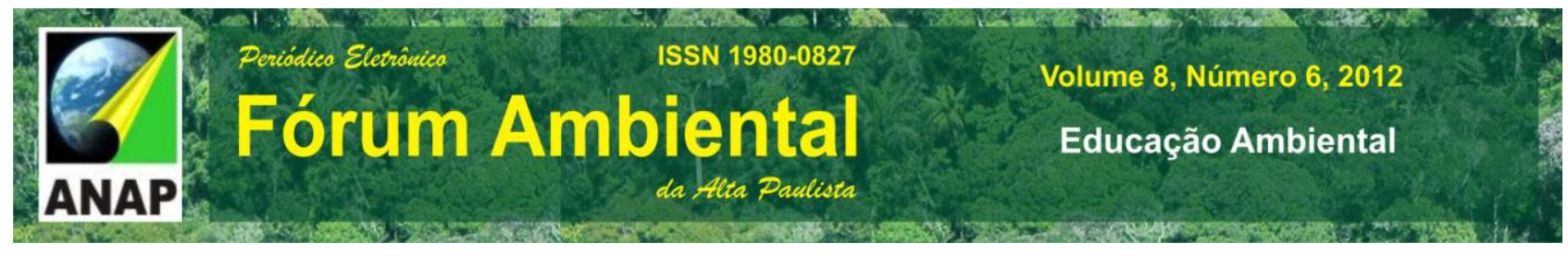

realizadas conversas informativas para que os moradores possam ampliar a compreensão ambiental dos mecanismos naturais que regem aquela realidade, ou seja, busca-se o entendimento da importância de áreas verdes para a qualidade ambiental, e, por consequência, a saúde ambiental do bairro.

O papel das ações de Educação Ambiental incentivada pelo grupo contribui, dessa maneira, para se formar cidadãos com responsabilidade na geração dos resíduos sólidos, na redução do consumo, na reutilização e no descarte seletivo de materiais consumidos. Também se tem trabalhado a importância das árvores para a nossa cidade como um bem coletivo e não um bem individual, pontual.

Outro aspecto que essa autora ressalta é a responsabilidade ambiental, ou seja: como os moradores de um bairro de uma cidade média, como Presidente Prudente, podem contribuir para a manutenção do planeta Terra?. Nessa mesma direção enfatizase a competência que é necessária adquirir para reivindicar do poder público, mais projetos, equipamentos, ações, e, consequentemente, mais saúde ambiental para o bairro.

Portanto, as ações de Educação Ambiental são desenvolvidas visando atender a todos esses objetivos para, assim, alcançar a cidadania ambiental.

A Educação Ambiental, segundo Rodriguez e Silva (2009) é tida como um dos instrumentos mais importantes e eficazes para a sociedade moderna superar a crise ambiental vivenciada em todo o Planeta. Enfatizam, ainda que, a Educação Ambiental em conjunto com outros instrumentos de planejamento e gestão do território, pode contribuir para o estudo e apontamento de soluções de inúmeros problemas ambientais.

Nessa perspectiva Leal (2008) coloca que a Educação Ambiental

[...] trata-se de instrumento de luta para empoderar os que querem mudar o mundo, para enfrentar as contradições sociais e a exploração econômica dos povos e países, para interferir na produção do espaço e na organização social e para fomentar as mudanças sociais e culturais necessárias para melhoria da qualidade ambiental e da qualidade de vida da população (Leal, 2008, p.44).

Com a execução desse projeto de Educação Ambiental almeja-se empoderar os moradores do bairro, ou seja, dar mais poderes para que essa população possa compreender o seu papel na sociedade e interferir na produção do seu espaço. 
É dessa maneira que esse grupo de Educação Ambiental "Amigas da Natureza" vem desenvolvendo o projeto "Um bairro melhor". A comunidade do bairro pode e deve exercer papel fundamental na construção do desenvolvimento sustentável.

As atividades desse projeto de Educação Ambiental estão sendo desenvolvidas com o apoio de dois grupos de pesquisa da Faculdade de Ciências e Tecnologia da UNESP/Presidente Prudente, o Laboratório de Biogeografia e Geografia da Saúde e o GADIS/Gestão Ambiental e Dinâmica Socioespacial. Esses grupos têm várias ações de pesquisa e de extensão universitária importantes no município e o seu apoio ao grupo Amigas da Natureza só vem somar e qualificar as ações de Educação Ambiental.

\section{OBJETIVO GERAL}

Entre os objetivos desse projeto estão: estimular a conscientização ambiental dos moradores em relação à limpeza da praça e do bairro; construção de conhecimentos para estabelecer novas relações sociedade-natureza, com mudanças de valores e atitudes em relação ao meio ambiente; planejar ações de intervenção no bairro - plantio de árvores, canteiros de flores; campanhas educativas para melhorar a coleta seletiva e do lixo comum etc.; comemorar o dia da praça com atividades culturais; incentivar talentos culturais do bairro (convidando-os para tocar, cantar, dançar ou fazer teatro na praça).

\section{A EXPERIÊNCIA DO PROJETO DE EDUCAÇÃO AMBIENTAL: A PRAÇA COMO LUGAR DAS AÇÕES AMBIENTAIS}

O bairro Jardim das Rosas está localizado na bacia do córrego do Limoeiro, importante afluente do Rio Santo Anastácio, próximo à Faculdade de Ciências e Tecnologia/FCT-UNESP, SESC-Thermas, Museu Municipal e Prudenshopping. Cercado, portanto, de instituições importantes de ensino e memória da cidade, assim como, grandes centros de lazer e consumo. 

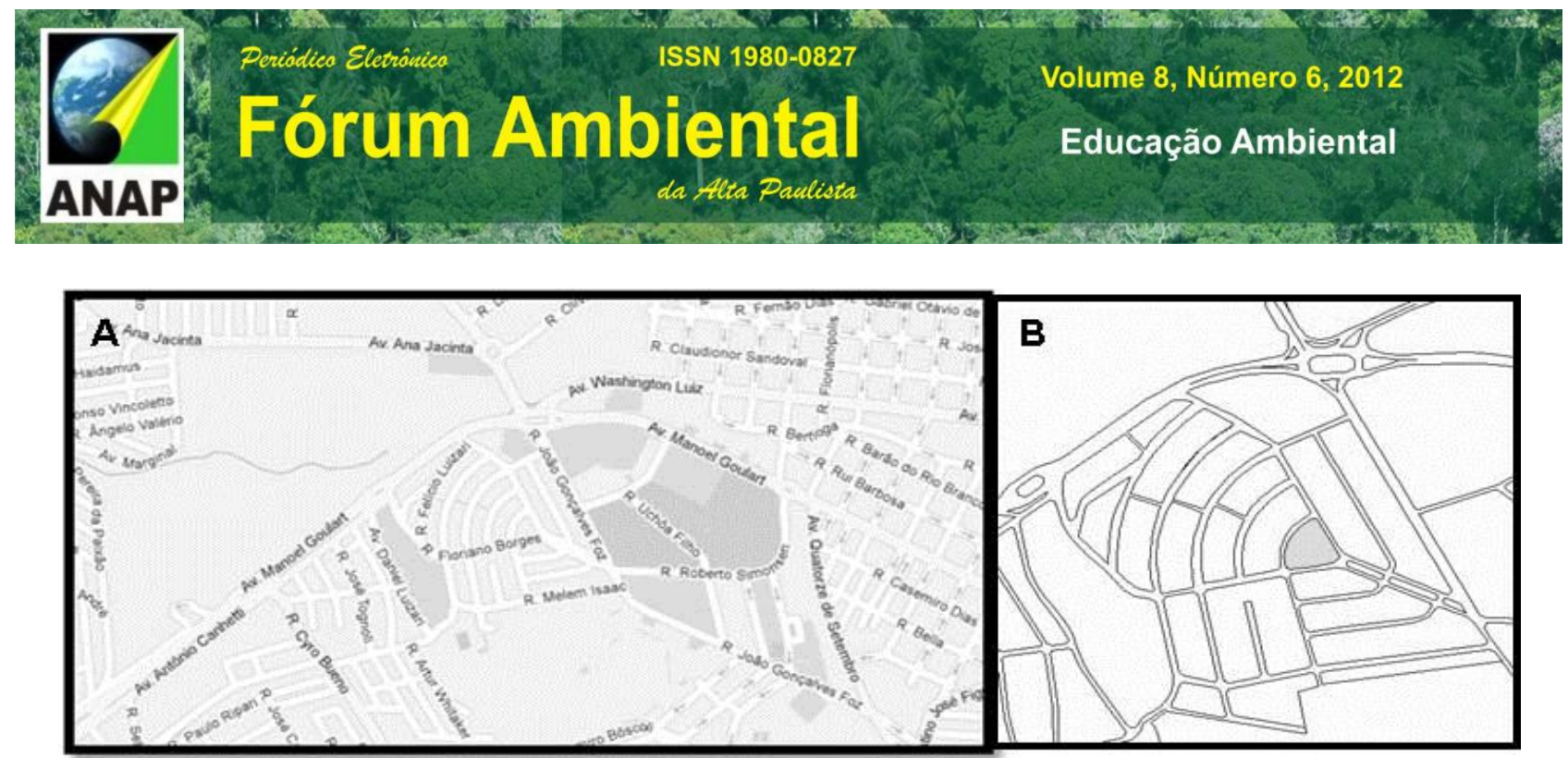

Figura 1. A e B: Localização do Jardim das Rosas em Presidente Prudente/SP.

A Praça dos Imigrantes, localizada nesse bairro, é a referência das ações de Educação Ambiental do Grupo de Educação Ambiental Amigas da Natureza. É um bairro considerado de meia idade na cidade, pois existe há mais de 40 (quarenta) anos e a praça já completou 26 anos de existência.

As ações ambientais realizadas são: mutirão de limpeza da praça - que é feito todo o encontro; o teatro ambiental infantil, realizado pelo grupo Amigas da Natureza, na qual produzem as suas próprias peças, fazem os cenários e dramatizam criando personagens e com fantoches etc.; reuniões de trabalho para planejar as ações e atividades; canteiros de flores, reutilizando pneus como floreiras; campanhas educativas para melhorar a coleta seletiva e do lixo comum, nessa fase inicial, o grupo optou conversas com os moradores, na praça e em algumas residências; comemoração do dia da praça com atividades ambientais e culturais etc. (Figuras 2 e 3 ).
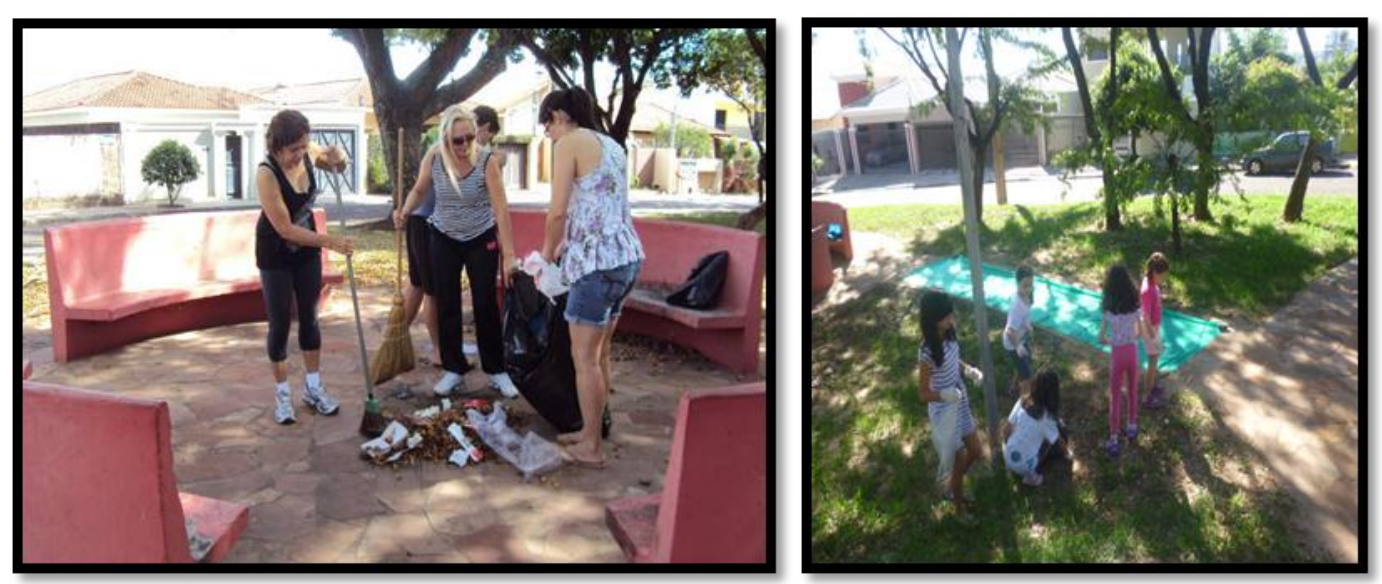

Figura 2. Grupo de moradores fazendo a varreção da praça. Fig.3. Crianças com luvas recolhendo lixo espalhado pelo gramado da praça. Fonte: Acervo pessoal (GUIMARÃES; SEOLIN DIAS, 2012). 


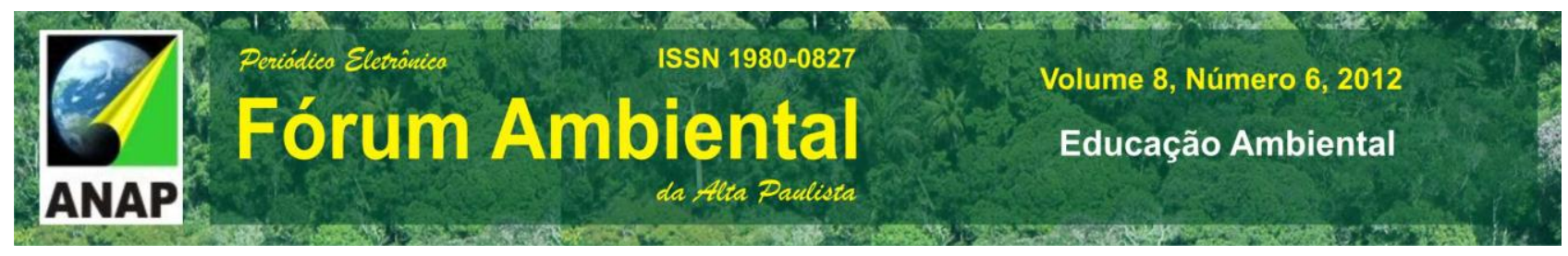

Outra ação de Educação Ambiental recém realizada pelo grupo foi um primeiro contato com a história da praça. A arquiteta responsável pelo projeto e desenho da praça relatou detalhes da história de saneamento dessa área destinada ao lazer (Figura 4. e 5.).
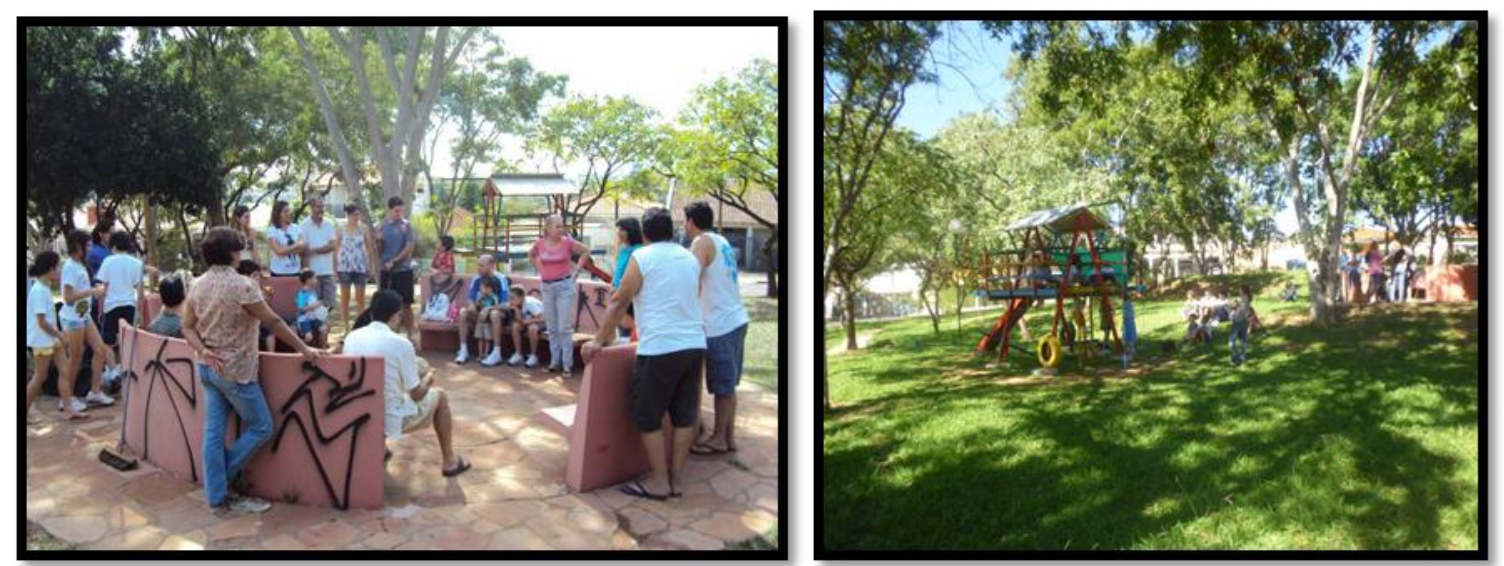

Figuras 4. Reunião com os moradores e a Arquiteta responsável pelo desenho da Praça dos Imigrantes. Fig. 5. Visão geral da praça. Fonte: Acervo pessoal (GUIMARÃES; SEOLIN DIAS, 2012).

Está sendo trabalhado a cada encontro a importância das árvores para a nossa cidade, como um bem coletivo. No primeiro encontro foi plantado um Ipê Amarelo, doado pela Secretaria de Meio Ambiente de Presidente Prudente, cujo crescimento vem sendo acompanhado pelas crianças do projeto, a cada encontro (Figura 6.). O projeto prevê o plantio de árvores na primeira etapa na praça e, depois, deve se estender para as calçadas e o morador que ainda não tem uma árvore na sua calçada vai poder participar da campanha "Adote uma árvore".

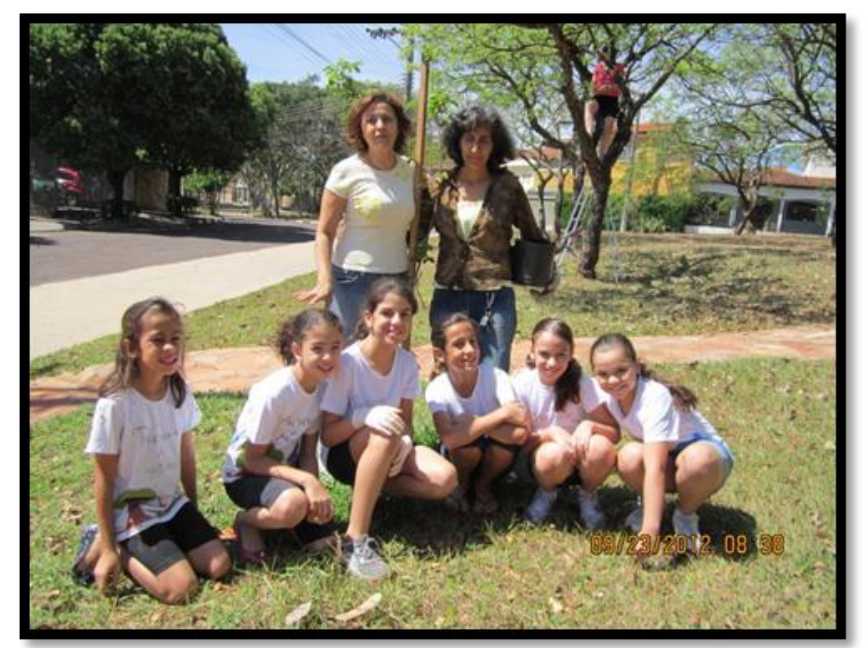

Figura 6. Grupo Amigas da Natureza ao lado do Ipê amarelo, árvore símbolo do projeto. Fonte: Acervo pessoal (GUIMARÃES; SEOLIN DIAS, 2012). 
O Grupo sempre organiza momentos culturais para os encontros, cabe registrar a oficina com estudantes da FCT/UNESP no qual foi ensinado como tocar músicas com instrumento feitos com materiais recicláveis. Lata de tinta vazia transforma em caixa de som e galão de óleo vira tambor, produzindo som e ritmo.
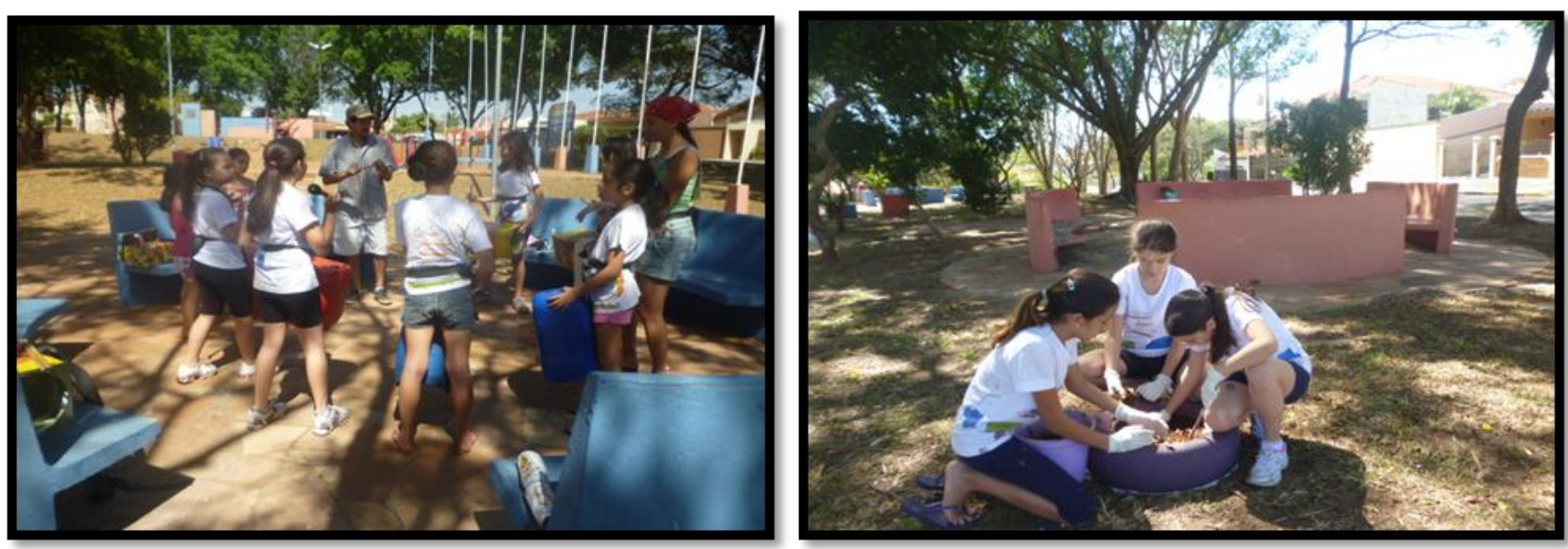

Figuras 7. e 8. Grupo "Amigas da Natureza" participando de oficina de música e plantio de flores em pneus. Fonte: Acervo pessoal (GUIMARÃES; SEOLIN DIAS, 2012).

Por fim, é necessário registrar que o projeto de Educação Ambiental do Grupo Amigas da Natureza é, sobretudo, um projeto de mobilização social, que visa adequar medidas e ações com objetivos específicos de alterar uma realidade local. Visa despertar a comunidade a implementar novos valores em contraponto com a atual realidade, gerando com isso mais preocupações com a preservação do meio ambiente.

\section{RESULTADOS}

O grupo de Educação Ambiental já coleciona alguns resultados positivos dessas ações ambientais, como por exemplo, a aquisição de um equipamento de lazer para as crianças e a colocação de quatro lixeiras na praça, além de, ampliar ainda mais a conscientização dos moradores; contribuir para a construção de novos conhecimentos e práticas sustentáveis para a melhoria da qualidade de vida do bairro.

Ressalta-se que o envolvimento dos moradores com o projeto é gradativa e aos poucos vai se fortalecendo os vínculos de amizade e de organização social. 
A Secretaria do Meio Ambiente do município tem um papel de parceria bastante importante com o grupo, o que facilita a prática de muitas ações ambientais já realizadas e o encaminhamento de outras, como por exemplo, a pintura de toda estrutura da praça, obtenção de um ponto de água para que seja possível a manutenção das plantas e mais equipamento de lazer para as crianças e jovens do bairro.

\section{CONSIDERAÇÕES FINAIS}

Os espaços de praças são muito ricos para a realização de encontros, trocas de conhecimento, ideias para a aprendizagem da Educação Ambiental e para fomentar o desenvolvimento sustentável de maneira descontraída, mas, comprometida com a seriedade que essas questões devem ser tratadas. Os moradores desse bairro, por sua vez, também valorizam esse espaço, pois acolheram o projeto "Um bairro melhor" com satisfação e oportunidade de garantir cada vez mais a qualidade ambiental para o bairro.

Evidencia-se, portanto, diante dos objetivos traçados para o projeto e dos resultados até agora colhidos, a necessidade de realizar trabalhos em longo prazo com os moradores e as crianças para efetivação de uma contribuição significativa para mudanças culturais, sociais e políticas públicas voltadas às práticas sustentáveis.

\section{REFERÊNCIAS}

BOFF, L. Sustentabilidade: o que é o que não é. Petrópolis, RJ : Vozes, 2012.

LEAL, A. C. Educação Ambiental, Águas e Resíduos Sólidos Urbanos. In: FISCARELLI, S. H.; ALAMATSU, J. I. (Org.). Metodologia de Projetos na Educação Ambiental. Metodologia de Projetos na Educação Ambiental. 1a. ed. São Paulo - SP: Páginas \& Letras Editora e Gráfica Ltda, v. 1, p. 43-62, 2008.

RODRIGUEZ, J. M. M.; Silva, E. V. Educação Ambiental e Desenvolvimento Sustentável: Problemática, Tendências e Desafios. Fortaleza. Editora UFC, 2009.

SATO, M. Educação Ambiental. 3 ed. São Carlos/SP: PPG-ERN/UFSC, 1985. 